\title{
Climate-driven hydrological variability determines inter-annual changes in stream invertebrate community assembly
}

Romain Sarremejane ${ }^{1,2}$, Heikki Mykrä ${ }^{4}$, Kaisa-Leena Huttunen ${ }^{1}$, Kaisa-Riikka Mustonen ${ }^{1}$, Hannu Marttila ${ }^{5}$, Riku Paavola ${ }^{6}$, Kalle Sippel ${ }^{7}$, Noora Veijalainen ${ }^{7}$ and Timo Muotka ${ }^{1,3}$

${ }^{1}$ Dept of Ecology and Genetics, Univ. of Oulu, PO BOX 3000, FI-90014, University of Oulu, Finland

${ }^{2}$ School of Science and Technology, Nottingham Trent Univ., Nottingham, UK

${ }^{3}$ Finnish Environment Inst., Oulu, Finland

${ }^{4}$ Finnish Environment Institute, Freshwater Centre, Oulu, Finland

${ }^{5}$ Water Resources and Environmental Engineering Research Unit, University of Oulu, Finland ${ }^{6}$ Oulanka Research Station, Kuusamo, Finland

${ }^{7}$ Finnish Environment Institute (SYKE), Freshwater Centre, Helsinki, Finland

Corresponding author: Romain Sarremejane, Dept of Ecology and Genetics, Univ. of Oulu, PO BOX 3000, FI-90014, University of Oulu, Finland. Email: romain.sarremejane@ oulu.fi

Decision date: 07-May-2018

This article has been accepted for publication and undergone full peer review but has not been through the copyediting, typesetting, pagination and proofreading process, which may lead to differences between this version and the Version of Record. Please cite this article as doi: [10.1111/oik.05329]. 


\begin{abstract}
Although flow regime is one of the major drivers of riverine communities, not much is known about how inter-annual variability and extremes of flow influence community assembly mechanisms. We used data on benthic macroinvertebrates and modelled flow regimes in 23 near-pristine boreal streams to assess how community assembly mechanisms and species occupancy varied in response to inter-annual variability in flow conditions across 11 successive years encompassing extreme (both low and high) flow events. A null model approach was used to test whether deterministic or stochastic processes dominated community assembly and how much regional (among-stream) flow variability contributed to community variability ( $\beta$-diversity). Mean daily flow and the greatest rate of flow rise were the strongest flow-related descriptors of invertebrate community composition. Communities were differentially assembled depending on the direction of change in flow magnitude: in highflow years, communities were more similar than expected by chance, while at low flows they tended to be more dissimilar than expected. Beta-diversity of macroinvertebrate communities was related to among-stream flow variability only at high flows. Common species correlated strongly with flow variability and contributed most to variation in $\beta$ diversity, suggesting that changes in assembly mechanisms are mainly driven by common species. While homogenization of communities in high-flow years reflected increased species occupancies and environmental sorting, increased turnover during low flows likely resulted from stochastic extinctions and dispersal limitation. Our findings suggest that extreme hydrological events exert a strong control over stream invertebrate community assembly, and their effect may be even more profound in the future as high and low-flow spells are expected to occur more frequently, not allowing time for communities to recover.
\end{abstract}

Keywords: $\beta$-diversity, flow regime, macroinvertebrates, meta-community, river network, temporal variability 


\section{Introduction}

Regional climatic variability is a major driver of community variability in both terrestrial and aquatic ecosystems (Bradley and Ormerod 2001, Pérez-Ramos et al. 2017). River ecosystems are particularly sensitive to climatic variability due to the intimate connection between the flow regime and precipitation-evapotranspiration balance (Poff et al. 1997). Although most riverine organisms tolerate variation in flow, extreme flood and drought events can alter their metabolic rates as well as community assembly mechanisms and ecosystem functioning (Woodward et al. 2016). Flow conditions have been identified as a major driver of the compositional variability of riverine communities (Lepori and Malmqvist 2009, Mustonen et al. 2016), yet little is known about how inter-annual variability and extremes of flow influence stream community assembly.

Community assembly results from a combination of deterministic (e.g. habitat filtering, biotic interactions) and stochastic (e.g. random colonization/dispersal, extinction) processes that vary in importance depending on, for example, environmental heterogeneity (Astorga et al. 2014), connectivity (Carrara et al. 2012, Sarremejane et al. 2017a) and disturbance (Lepori and Malmqvist 2009). Climate-driven flow variability creates a strong environmental filter that selects species with traits suitable to prevailing environmental conditions (Lytle and Poff 2004). While drought can affect communities through reduction of habitat size and changes in local conditions (Chase 2007), the effect of flooding is mediated by increased shear stress that enhances the mortality of less adapted species (Lake 2000). The outcome of flow extremes on community assembly may depend on how homogeneous flow conditions are across the landscape (Hawkins et al. 2015, Rolls et al. 2016). Species turnover ( $\beta$-diversity) should increase if disturbance increases environmental variability among sites (divergent selection) and decrease if the effect is homogeneous across the landscape (convergent selection) (Myers et al. 2015). Flow extremes can also result in stochastic 
assembly mechanisms if disturbance leads to species extinctions decoupled from trait selection, as has been reported at high disturbance intensities in both streams (Lepori and Malmqvist 2009) and ponds (Vanschoenwinkel et al. 2013). Lastly, extreme flows can affect community assembly through changes in dispersal rates if changes in flow influence habitat connectivity. While dispersal limitation (random extinction-colonization processes) may predominate under severe drought, i.e. at low hydrological connectivity, mass effects (high dispersal overriding environmental sorting) may be more pronounced during high flows (at high hydrological connectivity; Sarremejane et al. 2017b).

The effect of disturbances on community composition depends not only on species' tolerance of and resilience to disturbance but also on species' initial regional occupancy (McGlinn and Hurlbert 2012). While $\beta$-diversity decreases if only the most common species tolerate stressors, it can increase if common species are more sensitive than, or equally affected as, less frequent species (Hawkins et al. 2015). Although common species should be less prone to regional extinction and have better chances of recolonization after disturbance (Altermatt et al. 2011), they may also be locally more affected by stressors than are rare species. For example, Hawkins et al. (2015) showed that increased $\beta$-diversity of stream macroinvertebrates with increasing anthropogenic stress was associated with increased occupancies of rare but tolerant taxa and decreased occupancies of relatively common but sensitive species. Therefore, common species may sometimes be prone to local extinction but, due to their high regional occurrences, they may still be able to track environmental variability (Mykrä and Heino 2017).

We used data on benthic macroinvertebrates and modelled flow regimes in 23 nearpristine boreal streams to assess how community assembly mechanisms varied in response to inter-annual variability in flow conditions across 11 successive years (2000-2010) encompassing extreme (both low and high) flow events. We used a null model approach to 
test when (under which flow conditions) either deterministic or stochastic processes dominated community assembly and how much regional (among-stream) flow variability contributed to $\beta$-diversity. We expected flow-related environmental sorting to be stronger in both high and low flow years as a result of $(\mathrm{H} 1)$ convergent selection if flow conditions exceed the tolerance of many sensitive species, or as a result of $(\mathrm{H} 2)$ divergent selection if heterogeneity in regional flow conditions increases with extreme events (i.e. flow regimes among streams within a region do not change synchronously in response to drying or flooding). These contrasting mechanisms should result in a stronger relationship between community composition and flow conditions in years with either exceptionally high or low flows. Alternatively, if extreme events enhance the rate of random extinctions (thus increasing community dissimilarity), (H3) communities should show random variability along the flow gradient. We further expected (H4) the river network structure to have a stronger effect on community variability during low flow years when connectivity is low and dispersal limitation mechanisms should dominate. Finally, we assessed how species occupancy varied in response to flow variability and how such variability affects $\beta$-diversity. We hypothesized that (H5) common species should reflect flow variability more closely than do rare species because their high occurrences may indicate (i) a capacity to occupy suboptimal habitats where environmental variability is more likely to cause local extinction, or (ii) greater recolonization opportunities after disturbances.

\section{Material and Methods}

\section{Study sites and biological data}

We used macroinvertebrate data from 23 first-to-second order streams (catchment area 2.3 $\left.50.1 \mathrm{~km}^{2}\right)$ in the Koutajoki drainage basin in northeastern Finland $\left(66-67^{\circ} \mathrm{N}, 28-30^{\circ} \mathrm{E}\right.$, Fig 
S1). All the streams are in near-pristine condition with no marked riparian or hydromorphological alterations, with anthropogenic activities (mainly forestry) covering less than $10 \%$ of their catchments. The streams drain peatlands, coniferous and mixed forests, and are oligotrophic with alkaline to circumneutral water ( $\mathrm{pH}: 6.8$ to 8.0 ; total $\mathrm{P}: 3$ to $53 \mu \mathrm{g} \mathrm{L}^{-1}$ ). Linear distances between the sites range between 0.5 to $45.6 \mathrm{~km}$ (mean=16.8 km). Streams in this region are characterized by high flow seasonality with low flows during the winter, variable flows during the summer, snowmelt-induced peak flows in April to May and lower floods caused mainly by reduced evapotranspiration in the autumn (for a more detailed description of the study sites, see Huttunen et al. 2012).

Invertebrate samples were collected in late autumn (September-October) each year over an 11-yr period (2000-2010). Each sample consisted of a 2-min composite kick-sample (mesh size $0.3 \mathrm{~mm}$ ) covering most microhabitats present in a $\sim 50 \mathrm{~m}$ riffle section. This sampling effort covers ca. $1.3 \mathrm{~m}^{2}$ of the streambed and allows the detection of more than $70 \%$ of the invertebrate species present in a riffle (Mykrä et al. 2006). Invertebrates were sorted and identified in the laboratory, mainly to species or genus level. Chironomids were not identified beyond family level and were omitted from all statistical analyses.

\section{Hydrological modeling and flow characteristics}

We used the national scale model VEMALA (Huttunen et al. 2016) to calculate site-specific daily discharges for our study sites. VEMALA is based on a conceptual semi-distributed hydrological model, Watershed Simulation and Forecasting System (WSFS) (Vehviläinen 1994). VEMALA uses daily precipitation and temperature to predict daily flows using submodels accounting for precipitation, snow accumulation and melt, surface waters, water storages (soil and ground) and lake and river routing scheme. The model is constantly calibrated against an extensive national gauging network. 
We compiled modeled daily flows for a 2-month period prior to invertebrate sampling each year to calculate a set of hydrological variables describing stream flow characteristics (Table S1). Although flow conditions in the week preceding sampling have been shown to be a strong determinant of assembly mechanisms in such flashy environments as New Zealand streams, also longer periods of flow variability (several months) can affect stream community assembly (Campbell et al. 2015). As boreal streams are much less flashy environments, we chose a longer time period to make sure that the species collected by our samples would have experienced all major flow events typically encountered by their larval stages. We used five variables that have been previously identified to represent ecologically relevant components of the flow regime, both generally (Poff et al. 1997) and for Finnish rivers specifically (Mustonen et al. 2016): mean daily flow (MDF, $\mathrm{m}^{3} / \mathrm{s}$ ), coefficient of variation of mean daily flow (CV), total duration of high (HSD) and low flow spells (LSD) and the greatest rate of rise in flow (GRR, $\mathrm{m}^{3} /$ day) (Table $\left.\mathrm{S} 1\right)$.

\section{Statistical analyses}

Sample abundances varied widely (34 to 9209 individuals per sample); therefore, to eliminate dependence of species richness from raw abundances and also to downweight the relative importance of rare species, we rarefied all invertebrate samples to 300 individuals.

We used tests of homogeneity of dispersion (PERMDISP, see Anderson et al., 2006) with Sørensen dissimilarity on presence-absence data to assess among-year differences in $\beta$ diversity of macroinvertebrate assemblages. PERMDISP uses the analysis of variance Fstatistic to compare among-group distances to group centroid in the ordination space (Principal Coordinates Analysis) and tests the significance of among-group differences through permutation (here 999) of least square residuals. 
To assess whether average $\beta$-diversity in each year differed from random, we used a null model to simulate random communities (Chase and Myers 2011, Myers et al. 2013). We assumed that a species observed in any stream in any year is part of the regional species pool and all samples were thus included in a single null model. If, in any year, the observed mean $\beta$-diversity was more (or less) similar than random, we assumed that $\beta$-diversity was driven by deterministic mechanisms. In contrast, if community variability did not differ from random, we assumed that community assembly was dominated by stochastic processes. Null models were generated using presence-absence data on a quasiswap algorithm which conserves both original species frequencies and site-specific species richness (Miklós and Podani 2004). All dissimilarity measures are influenced by differences in species richness and null models with fixed richness are used to take into account these differences. If the factor of interest affects $\alpha$-diversity, it is impossible to determine if a change in $\beta$-diversity is due to differences in the underlying assemblage processes or amongsite differences in $\alpha$-diversity (see Chase et al. 2011). Null $\beta$-diversity ( $\beta_{\text {null }}$ ) was calculated as the mean Sørensen dissimilarity across the 999 simulated communities. To assess significance of the difference between the observed and null $\beta$-diversity, observed mean $\beta$-diversity $\left(\beta_{\mathrm{obs}}\right)$ was compared to $95 \%$ confidence intervals of the mean dissimilarities derived from the randomly generated 999 mean dissimilarities for each year. We also calculated departure of the observed mean $\beta$-diversity from the null expectation, expressed as standardized effect size $\left(\operatorname{SES}=\left(\beta_{\text {obs } \_} \beta_{\text {null }}\right) / \operatorname{SD} \beta_{\text {null }}\right)$. To determine if changes in assembly mechanisms were related to regional flow conditions we used linear regressions with SES as the dependent variable and regional averages (across sites) of each flow variable as independent variables. To determine which variable (or combination of variables) was most related to SES we used adjusted $\mathrm{R}^{2}$ and Akaike Information Criterion with smallsample correction (AICc), the best model being the one with the lowest AICc score. Models 
with $\triangle \mathrm{AICc}<2$ were interpreted as having equal support. Because annual averages of some flow variables were strongly intercorrelated we only included the least correlated variables in our candidate models (i.e. MDF, GRR and LSD, all $\mathrm{r}<0.70$ ).

To assess if $\beta$-diversity resulted from flow-related environmental sorting or dispersal processes along the river network, we built separate null models for each year and assessed the relationship between the deterministic part of the $\beta$-diversity (deviations from null) and the within-region flow variability. Separate null models for each year were used to avoid confounding factors related to inter-annual variation in the regional species pool. Yearly null models were built similarly as the global null model described above but instead of calculating SES on mean annual $\beta$-diversity, we calculated deviations from pair-wise dissimilarities ( $\beta$-deviation, e.g. Mykrä et al. 2017). To examine the strength of the relationship between community variability and environmental gradients and network configuration we used Mantel and partial Mantel tests (Pearson's coefficient) between $\beta$ deviation matrices and environmental (flow) or network distance matrices, with 999 permutations. We used Euclidean distances between standardized flow variables as our measure of environmental distance. We used BIOENV analysis (Clarke and Ainsworth 1993 ) to select the subset of flow variables that correlated most with community dissimilarity in each year. To assess if network configuration affected community assembly we measured network distance as the minimum distance between each pair of sites following the river network, using a digitized stream network map (ECRIN database EcrRiv.mdb) and the Network Analyst extension in ARCGIS 10.0. In case of significant spatial structuring of environmental variables (i.e. significant Mantel correlation between environmental and network distances in a given year), partial Mantel test was used to assess the effect of environmental distance on community dissimilarity while controlling for network distance, and vice versa. We then performed linear regressions between annual Mantel 
correlation coefficient (Mantel r; environmental vs community dissimilarity: Mantel renv) and regional averages of flow variables to determine if the strength of the relationship between flow conditions and community variability (flow-related environmental sorting) was related to inter-annual flow characteristics. Similarly, we assessed if the strength of the relationship between community dissimilarity and network distance varied with flow conditions by conducting linear regressions between Mantel $r$ (network distance vs community dissimilarity: Mantel r-net) and regional average of flow variables. Null model and Mantel test analyses were also performed on log transformed abundances using Bray-Curtis dissimilarity and a quantitative null model (swsh_both_r algorithm, function oecosimu in package vegan) but as the differences were generally minor, we only present these results where they differed from the presence-absence based patterns.

We also tested the relationship between mean annual (across-stream) flow variability and average MDF to assess if regional flow heterogeneity varied with flow magnitude. Across-stream flow variability was calculated as the average environmental distance of each stream to its centroid, separately for each year, using PERMDISP.

\section{Species occupancy}

We classified species based on their occupancy to assess separately the responses of rare vs common species to flow variability and to examine how changes in occurrence were related to community assembly. Frequency of occurrence for a species was calculated as the average number of sites occupied each year (considering only the years when the species was found in our samples) divided by the total number of sites. We then divided the species in three occupancy classes: rare (frequency between 0.05 and 0.2 , to exclude very rare taxa), intermediate (0.4 to 0.6$)$ and common (>0.8). Linear regressions were 
performed between average class frequencies and yearly means of flow variables and SES values, separately for each class. In addition, we performed linear regressions for a few key taxa in each status class to demonstrate species-specific in responses to flow variables.

All analyses were performed using R software. Rarefaction, PERMDISP, null models, mantel and partial mantel tests and BIOENV analyses were performed using functions rarefy, betadisper, oecosimu, mantel(.partial) and bioenv, respectively, in package vegan (Oksanen et al. 2015).

\section{Results}

Flow conditions

Mean daily flow in 2003 and 2006 was extremely low (lowest recorded in the past 30 years) (Fig. 1a), with exceptionally long periods of low spell particularly in 2006 (Fig. 1b). Conversely, relatively high mean daily flow and high rate of flow rise characterized years 2007 to 2010 (Fig. 1a and c). In all other years, flow conditions did not deviate strongly from long-term mean values.

\section{Diversity patterns}

A total of 89 species was recorded for the whole study period, with cumulative richness across the 23 sites varying between 70 and 84 species a year. Mean site richness varied between $23 \pm 1.7$ (1 SE; 2006) and 33 \pm 1.2 (2010) (Table 1). The observed mean $\beta$-diversity varied significantly across years (PERMDISP: $\mathrm{F}_{10,242}=3.283, \mathrm{P}<0.001$ ), ranging from 0.41 to 0.54 (Table 1 ). Null model results revealed that communities were more dissimilar than expected by chance in 2002 and 2003, more similar than expected in 2007 to 2009 , and no different from random expectation in 2000, 2001,2004, 2005 and 2010. In 2006, 
the difference bordered at significance $(\mathrm{p}=0.05)$, communities being then weakly more dissimilar than expected by chance. SES values of mean $\beta$-diversity were strongly negatively related to mean daily flow (MDF) $\left(\mathrm{R}^{2} \mathrm{adj}=0.79\right.$; Fig. 2, Table $\left.\mathrm{S} 2\right)$, suggesting that, as discharges increased, communities became more similar than expected by chance. Results based on abundance data (Bray-Curtis distances) showed a slightly different pattern: also then, communities were more dissimilar than expected by chance in 2002, 2003 and 2006 but were no different from random in all other years.

\section{Community variability vs flow variability and network structure}

Flow-related environmental distance and network distance were correlated in 2002, 2004 and from 2006 to 2010 (Table 2) and thus partial Mantel tests were used for these years.

Environmental distances were significantly related to deviations of pairwise dissimilarities ( $\beta$ deviations) in all years except 2003, 2005 and 2006 (Table 2, Fig. S2). Mean daily flow (10 times of 12) and the greatest rate of rise (seven times) were the most often selected (by BIOENV) descriptors of community composition (Table 2). MDF and LSD were equally strong correlates of Mantel r-env (Table S2), meaning that flow-related environmental selection increased with flow magnitude (Fig. 3a) and decreased with the duration of low flows (Fig. 3b). Network distance correlated weakly with $\beta$-deviations only in 2003 and 2005 (Table 2, Fig. S3). MDF was strongly correlated to Mantel r-net (Table S2, $\mathrm{R}^{2}=0.79$ ), indicating that communities were more structured along the river network at low than at high flows. Mean annual flow variability across streams was weakly positively related to flow magnitude $\left(\mathrm{P}=0.045, \mathrm{R}^{2} \mathrm{adj}=0.304\right)$, indicating that flow conditions were more homogeneous at low flows and that increase/decrease in community dissimilarity may be related to changes in within-region flow heterogeneity. 


\section{Species occupancies}

Frequency of occurrence was low (0.05 to0.20) for 41 species, while 15 had intermediate (0.40-0.60) and six high (>0.80) occupancies. Different occupancy classes were related to partly different flow descriptors. The occupancy of rare species was mostly related to GRR but even then the pattern was relatively weak (Fig. 4a, Table S2). Intermediate species' occupancies were best predicted by MDF and GRR (positive relationship) (Fig. $4 \mathrm{a}$ and $4 \mathrm{~b}$ ) whereas common species were strongly positively related to MDF (Fig. 4b, Table S2). Occupancies of rare species were unrelated to SES values $\left(R^{2} \operatorname{adj}=0.05\right)$ whereas intermediate $\left(R^{2} a d j=0.44\right)$ and common species $\left(R^{2}\right.$ adj $\left.=0.68\right)$ were negatively related to SES, indicating that their increased regional occurrence homogenized invertebrate communities (Fig. 4c).

The occupancy of several individual taxa correlated strongly with at least one of the flow variables (Table S3). While the occupancy of the most common taxa (i.e. Simuliidae and Baetis rhodani) decreased strongly with increasing duration of low-flow spell (Fig. 5a,b), the responses of intermediate and rare taxa were more variable. For example, the occupancy of the caddis larvae Hydropsyche saxonica and Silo pallipes decreased with decreasing mean daily flow, while that of the mayflies Leptophlebia sp. and Centroptilum luteolum decreased with increasing mean daily flow or increased with low-spell duration, respectively (Fig 5c-f).

\section{Discussion}

As expected, macroinvertebrate community composition differed from random expectation in years with exceptionally high or low flows. The relationships between null model deviations (SES values) and flow characteristics were generally strong, suggesting that community assembly mechanisms varied inter-annually along a flow condition 
gradient. However, communities were differentially assembled depending on the direction of change in flow magnitude: at high flows, communities were more similar than expected by chance (partly supporting hypothesis $\mathrm{H} 1$ ), while at low flows they tended to be more dissimilar than expected. There was no indication of species extinctions in high-flow years, suggesting that increased community similarity resulted from increased regional occurrences rather than selective extinctions. By contrast, weak sorting of species along flow gradients in low-flow years suggests that increased $\beta$-diversity then largely resulted from random extinctions, thus supporting our hypothesis H3. Furthermore, river network structure tended to have a stronger effect on community variability during low flows, potentially indicating the predominance of dispersal limitation then (H4). Consistent with hypothesis H5, occupancies of common and, to a lesser degree, intermediate species were strongly correlated with flow conditions. Interestingly, while common taxa responded consistently negatively to low flows, intermediate and rare taxa responded variably, and in some cases positively, to reduced flows. Our results thus suggest that while inter-annual changes in flow conditions can modify stream macroinvertebrate communities, the outcome of exceptional flow events can be different depending on the direction and magnitude of flow changes, as well as on species initial occupancy.

High flows are usually considered less harmful than drought to aquatic communities since riverine organisms may be better equipped for coping with an excess of water than with the loss of it (Woodward et al. 2016). Extreme flows should affect communities primarily through environmental sorting by filtering out less adapted species from the regional species pool (Chase 2007, Lepori and Malmqvist 2009). Communities at high flows were more similar than expected by chance but this did not result from regional homogenization of flow conditions since variability of flow across sites was positively related to flow magnitude. There were no major floods during the study period and although high flows did influence 
community assembly, even the highest discharges were likely too low to cause species extinctions. High summertime flows may in fact increase the availability of habitats for new colonists, thus resulting in increased community similarity through increased occupancy of several species from the regional species pool.

Flow extremes may also lead to random extinctions if species losses are decoupled from trait selection (Lepori and Malmqvist 2009). Due to random extinctions species can be absent from otherwise suitable habitats, resulting in higher community variability than expected by chance. Drought-resistant species are common in arid regions and selection should favor those species under drying conditions. In boreal regions, where droughts are less intense and frequent, few species possess drought-resistance strategies and extinction decoupled from selection should therefore be more likely in boreal streams. Indeed, we found invertebrate communities to be more dissimilar than expected by chance at low flows, with no relation to flow variables. However, the frequency of some taxa (e.g. Baetis rhodani, Simuliidae and Hydropsyche saxonica) that typically occur in fast flowing riffles, decreased significantly with decreasing discharges and increasing duration of low flows, suggesting that selective extinctions related to flow may have occurred regionally. Selective extinctions related to other factors than flow heterogeneity may also be responsible for this pattern. Drought can affect local conditions differentially in different streams depending on stream size and habitat characteristics, and streams may therefore become structurally more dissimilar during droughts. This in turn may result in communities being more dissimilar than expected by chance under drought (Rolls et al. 2016). Huttunen et al. (2017) showed that temporal stability of macroinvertebrate communities in these same streams was enhanced by the presence of aquatic bryophytes, suggesting that the effects of flow extremes can be mitigated by local habitat factors. Flow can also affect dispersal and therefore community assembly through hydrological connectivity (Datry et al. 2016, Rolls 
et al. 2016). The increasing effect of network structure under low flows suggests that reduction of flow reduced connectivity, leading to increased rates of random extinction in these relatively isolated headwater communities (Mouquet and Loreau 2003).

Interestingly, the occupancy of some intermediate and rare taxa increased under low flows (e.g. Leptophlebia sp. and Centroptilum luteolum mayflies), suggesting that some species may benefit from drought. C. luteolum is typically found in pools and lake shores (Bagge 1999) and it may have benefited from the increased availability of more lentic habitats during low flows. Leptophlebiidae mayflies are relatively tolerant of drying (Chadd et al. 2017) and often occur in lentic and slow-flowing habitats (Fontaine et al. 1990, Salmela and Savolainen 2013); therefore their increased occurrence under low flows may not be that surprising.

As expected, regionally common species showed stronger relationships to flow than did species with more sporadic occurrence, suggesting that common species are better able to track environmental changes. High flows led to an increased occupancy of common species whereas low flows decreased their occupancy. The high occurrence of common species may indicate their capacity to withstand variable environmental conditions or to occupy habitats at the margins of their niches where they may be more vulnerable to environmental change (McDermott Long et al. 2017). Common species may also have more post-disturbance recolonization opportunities due to their wide occurrence across the landscape. They may thus be sensitive to, but able to recover from, disturbances, which likely explains their strong relationship with flow variability. Rare species not only comprise habitat specialists but also species that, due to mass effects, sporadically subsist in unsuitable habitats (e.g, lentic species) (Sgarbi and Melo 2017), potentially explaining their random variation along hydrological gradients. We also observed that the occupancy of common and intermediate species correlated with community assembly mechanisms 
(SES), confirming that variation in the occupancy of the commonest species likely drives regional patterns of community variability (see McGlinn and Hurlbert 2012, Roque et al. 2016). It should be noted, however, that although our sampling method effectively captures most species present in a riffle, some of the rarest taxa, many of which occur only sporadically in streams, remain undetected (Mykrä et al. 2006). One could also argue that sampling only one riffle per stream is not enough to quantify among-stream differences in temporal community variability. Indeed, Heino et al. (2004) showed that macroinvertebrate communities may differ between successive riffles within a stream but they also showed that variability between different streams within a region is substantially higher.

We showed that late-summer flow conditions were a strong predictor of macroinvertebrate community variability and that there was a continuum of mechanisms assembling communities along a climate driven gradient in hydrological conditions. Macroinvertebrate communities were assembled by different mechanisms depending on flow conditions: environmental sorting in wet years, random extinctions in dry years. Accordingly, community assembly can result from different mechanisms depending on prevailing hydrological conditions, suggesting that assembly mechanisms are highly context dependent and temporally variable. This finding implies that a single sampling event may not allow a reliable assessment of community-environment relationships, particularly if conducted in hydrologically exceptional years (see also Mykrä et al. 2008). Due to the ongoing climate change, flow regimes have already changed and are expected to change even more in the future (Stagge et al. 2017, Blöschl et al. 2017) potentially leading to major alterations in invertebrate assemblages (Mustonen et al. 2018). Our results suggest that such changes in hydrological regimes can indeed reorganize stream communities. The effect of extreme events could be even more dramatic if high and low-flow years occur more frequently, not allowing time for communities to recover (Woodward et al. 2015). Research 
on the resilience of stream metacommunities to, and their assembly mechanisms from, hydrologically extreme events is needed but, at the present stage of knowledge, preserving natural hydrological regimes and network connectivity seem to be critical measures for protecting stream ecosystems against climate change.

\section{Acknowledgements}

We thank Oulanka Research Station for logistical support during fieldwork. We also thank the students and colleagues that helped collecting the benthic samples and also in the lab. We acknowledge Jari Oksanen and Patrick Saccone for statistical advice and an anonymous referee for constructive comments on a previous draft of the paper. This study was financially supported by the University of Oulu Graduate School (UniOGS).

\section{References:}

Altermatt, F. et al. 2011. Effects of connectivity and recurrent local disturbances on community structure and population density in experimental metacommunities. - PLoS One 6: e19525.

Astorga, A. et al. 2014. Habitat heterogeneity drives the geographical distribution of beta diversity: the case of New Zealand stream invertebrates. - Ecol. Evol. 4: 2693-2702.

Bagge, P. 1999. Mayflies (Ephemeroptera) of the Lake Saimaa complex (Eastern Finland). Proc. XXIV Nord. Congr. Entomol.: 210.

Blöschl, G. et al. 2017. Changing climate shifts timing of European floods. - Science 357: $588-590$.

Bradley, D. C. and Ormerod, S. J. 2001. Community persistence among stream invertebrates tracks the North Atlantic Oscillation. - J. Anim. Ecol. 70: 987-996.

Campbell, R. E. et al. 2015. Flow-related disturbance creates a gradient of metacommunity types within stream networks. - Landsc. Ecol. 30: 667-680. 
Carrara, F. et al. 2012. Dendritic connectivity controls biodiversity patterns in experimental metacommunities. - Proc. Natl. Acad. Sci. U. S. A. 109: 5761-5766.

Chadd, R. P. et al. 2017. An index to track the ecological effects of drought development and recovery on riverine invertebrate communities. - Ecol. Indic. 82: 344-356.

Chase, J. M. 2007. Drought mediates the importance of stochastic community assembly. Proc. Natl. Acad. Sci. 104: 17430-17434.

Chase, J. M. and Myers, J. A. 2011. Disentangling the importance of ecological niches from stochastic processes across scales. - Philos. Trans. R. Soc. Lond. B. Biol. Sci. 366: 23512363.

Chase, J. M. et al. 2011. Using null models to disentangle variation in community dissimilarity from variation in $\alpha$-diversity. - Ecosphere 2: art24.

Clarke, K. R. and Ainsworth, M. 1993. A method of linking multivariate community structure to environmental variables. - Mar. Ecol. Prog. Ser. 92: 205-219.

Datry, T. et al. 2016. Towards understanding the organisation of metacommunities in highly dynamic ecological systems. - Oikos 125: 149-159.

Fontaine, J. et al. 1990. Some aspects of the ecology of Leptophlebia Vespertina (L.) (Ephemeroptera: Leptophlebiidae). - In: Mayflies and stoneflies: Life histories and biology. Springer Netherlands, pp. 275-280.

Hawkins, C. P. et al. 2015. Environmental disturbance can increase beta diversity of stream macroinvertebrate assemblages. - Glob. Ecol. Biogeogr. 24: 483-494.

Huttunen, K.-L. et al. 2012. Temporal variability in taxonomic completeness of stream macroinvertebrate assemblages. - Freshw. Sci. 31: 423-441.

Huttunen, I. et al. 2016. A national-scale nutrient loading model for Finnish watershedsVEMALA. - Environ. Model. Assess. 21: 83-109.

Huttunen, K.-L. et al. 2017. Habitat connectivity and in-stream vegetation control temporal 
variability of benthic invertebrate communities. - Sci. Rep. 7: 1448.

Lake, P. S. 2000. Disturbance, patchiness, and diversity in streams. - J. North Am. Benthol. Soc. 19: 573-592.

Lepori, F. and Malmqvist, B. 2009. Deterministic control on community assembly peaks at intermediate levels of disturbance. - Oikos 118: 471-479.

Lytle, D. A. and Poff, N. L. 2004. Adaptation to natural flow regimes. - Trends Ecol. Evol. 19: 94-100.

McDermott Long, O. et al. 2017. Sensitivity of UK butterflies to local climatic extremes: which life stages are most at risk? - J. Anim. Ecol. 86: 108-116.

McGlinn, D. J. and Hurlbert, A. H. 2012. Scale dependence in species turnover reflects variance in species occupancy. - Ecology 93: 294-302.

Miklós, I. and Podani, J. 2004. Randomization of presence-absence matrics: comments and new algorithms. - Ecology 85: 86-92.

Mouquet, N. and Loreau, M. 2003. Community patterns in source-sink metacommunities. Am. Nat. 162: 544-557.

Mustonen, K.-R. et al. 2016. Defining the natural flow regimes of boreal rivers: relationship with benthic macroinvertebrate communities. - Freshw. Sci. 35: 559-572.

Mustonen, K.-R. et al. 2018. Thermal and hydrologic responses to climate change predict marked alterations in boreal stream invertebrate assemblages. - Glob. Chang. Biol. in press.

Myers, J. A. et al. 2013. Beta-diversity in temperate and tropical forests reflects dissimilar mechanisms of community assembly. - Ecol. Lett. 16: 151-157.

Myers, J. A. et al. 2015. Disturbance alters beta-diversity but not the relative importance of community assembly mechanisms. - J. Ecol. 103: 1291-1299.

Mykrä, H. and Heino, J. 2017. Decreased habitat specialization in macroinvertebrate 
assemblages in anthropogenically disturbed streams. - Ecol. Complex. 31: 181-188.

Mykrä, H. et al. 2006. The effect of sample duration on the efficiency of kick-samplingin two streams with contrastingsubstratumheterogeneity. - Verh. Int. Ver. Theor. Angew. Limnol. 29: 1351-1355.

Mykrä, H. et al. 2008. Concordance of stream macroinvertebrate assemblage classifications: How general are patterns from single-year surveys? - Biol. Conserv. 141: 1218-1223.

Mykrä, H. et al. 2017. Environmental degradation results in contrasting changes in the assembly processes of stream bacterial and fungal communities. - Oikos 126: 12911298.

Oksanen, A. J. et al. 2015. Vegan: Community Ecology Package. R package version 2.2-1. http://vegan.r-forge.r-project.org. in press.

Pérez-Ramos, I. M. et al. 2017. Climate variability and community stability in Mediterranean shrublands: the role of functional diversity and soil environment. - J. Ecol. 105: 13351346.

Poff, N. L. et al. 1997. The natural flow Regime: a paradigm for river conservation and restoration. - Bioscience 47: 769-784.

Rolls, R. J. et al. 2016. Unravelling the joint effects of flow regime, climatic variability and dispersal mode on beta diversity of riverine communities. - Freshw. Biol. 61: 13501364.

Roque, F. de O. et al. 2016. Deconstructing richness patterns by commonness and rarity reveals bioclimatic and spatial effects in black fly metacommunities. - Freshw. Biol. 61: 923-932.

Salmela, J. and Savolainen, E. 2013. New records of Paraleptophlebia werneri Ulmer, 1920 and P. strandii (Eaton, 1901) from Finland (Ephemeroptera, Leptophlebiidae). Biodivers. Data J. 1: e969. 
Sarremejane, R. et al. 2017a. Habitat connectivity and dispersal ability drive the assembly mechanisms of macroinvertebrate communities in river networks. - Freshw. Biol. 62: 1073-1082.

Sarremejane, R. et al. 2017b. Do metacommunities vary through time? Intermittent rivers as model systems. - J. Biogeogr.: 2752-2763.

Sgarbi, L. and Melo, A. S. 2017. You don't belong here: explaining the excess of rare species in terms of habitat, space and time. - Oikos in press.

Stagge, J. H. et al. 2017. Observed drought indices show increasing divergence across Europe. - Sci. Rep. 7: 1-10.

Vanschoenwinkel, B. et al. 2013. Disturbance regime alters the impact of dispersal on alpha and beta diversity in a natural metacommunity. - Ecology 94: 2547-2557.

Woodward, G. et al. 2015. Resilience of a stream community to extreme climatic events and long-term recovery from a catastrophic flood. - Freshw. Biol. 60: 2497-2510.

Woodward, G. et al. 2016. The effects of climatic fluctuations and extreme events on running water ecosystems. - Philos. Trans. R. Soc. B 371: 20150274. 


\section{Figure Legends}

Fig. 1: Averages (across 23 sites) ( $\pm 1 \mathrm{SE}$ ) of (a) mean daily flow (MDF, $\left.\mathrm{m}^{3} / \mathrm{s}\right),(\mathrm{b})$ low spell total duration (LSD, number of days) and (c) greatest rate of rise (GRR, $\mathrm{m}^{3} / \mathrm{day}$ ) calculated on July-to-August discharges for years 1981 to 2010. The vertical dashed line represents the start year of invertebrate sampling.
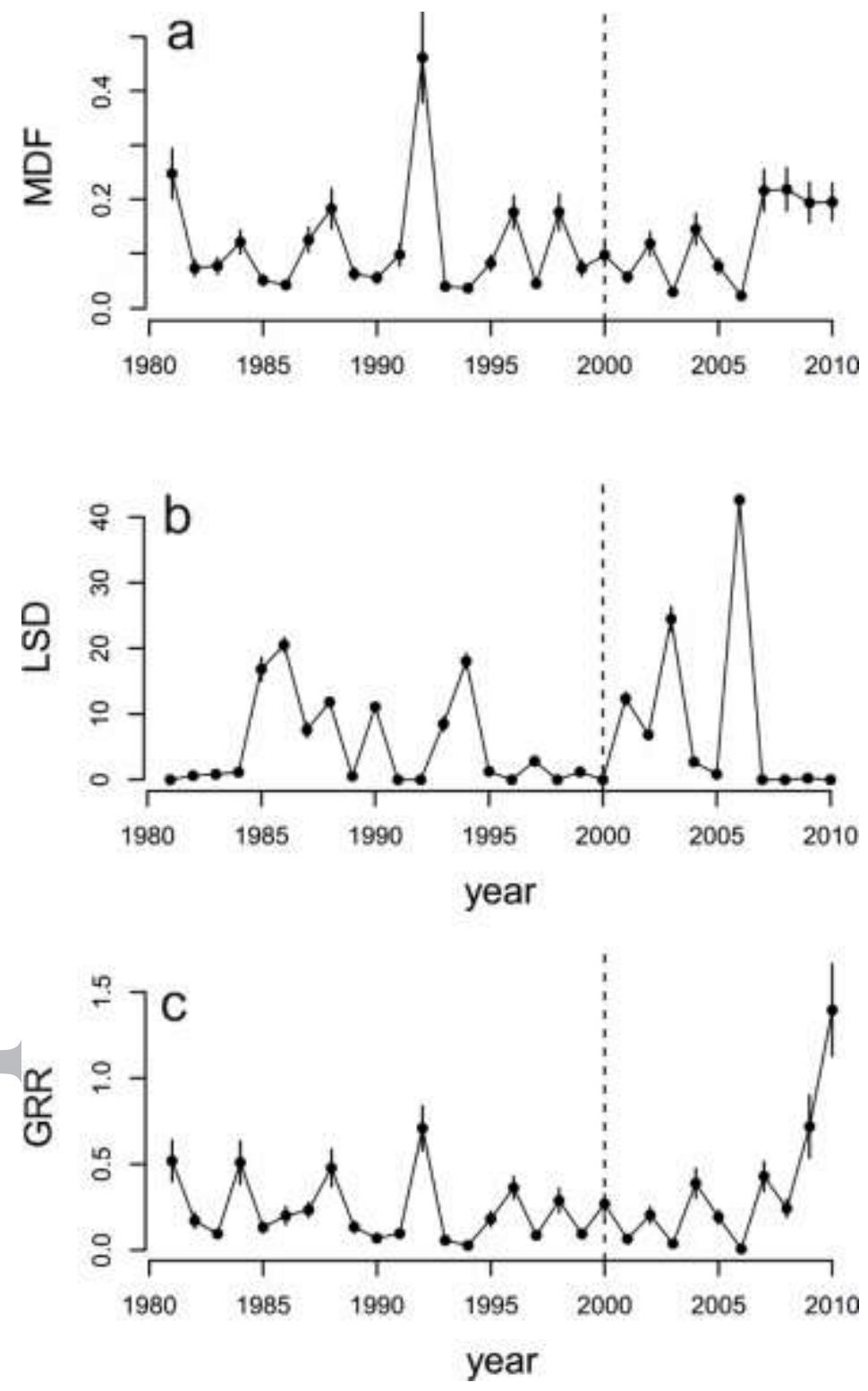

'This article is protected by copyright. All rights reserved.' 
Fig. 2: Linear regression between deviations of observed $\beta$-diversity from null expectation (SES values) vs. annual averages for mean daily flow (MDF). Observations above the grey belt had significantly positive (i.e. communities more dissimilar than expected by chance) and those below significantly negative (i.e. communities more similar than expected by chance) SES values. Observations within the belt do not differ from random expectati

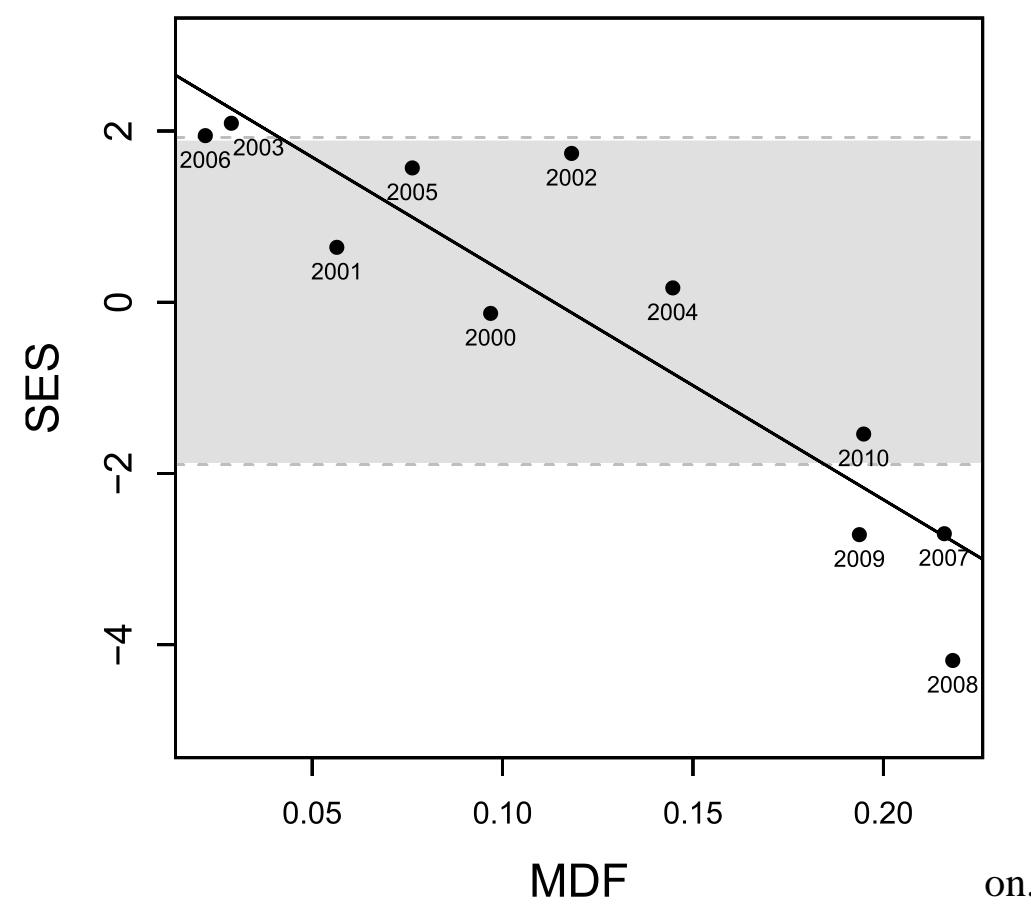


Fig. 3: Linear regressions between mantel correlation coefficient (Mantel r-env: $\beta$-deviations vs. environmental distances (a,b); Mantel r-net: $\beta$-deviations vs. network distances (c)) and annual averages for (a, c) mean daily flow (MDF) and (b) low-flow spell total duration (LSD). Mantel correlation was non-significant for the years located within the grey belt.

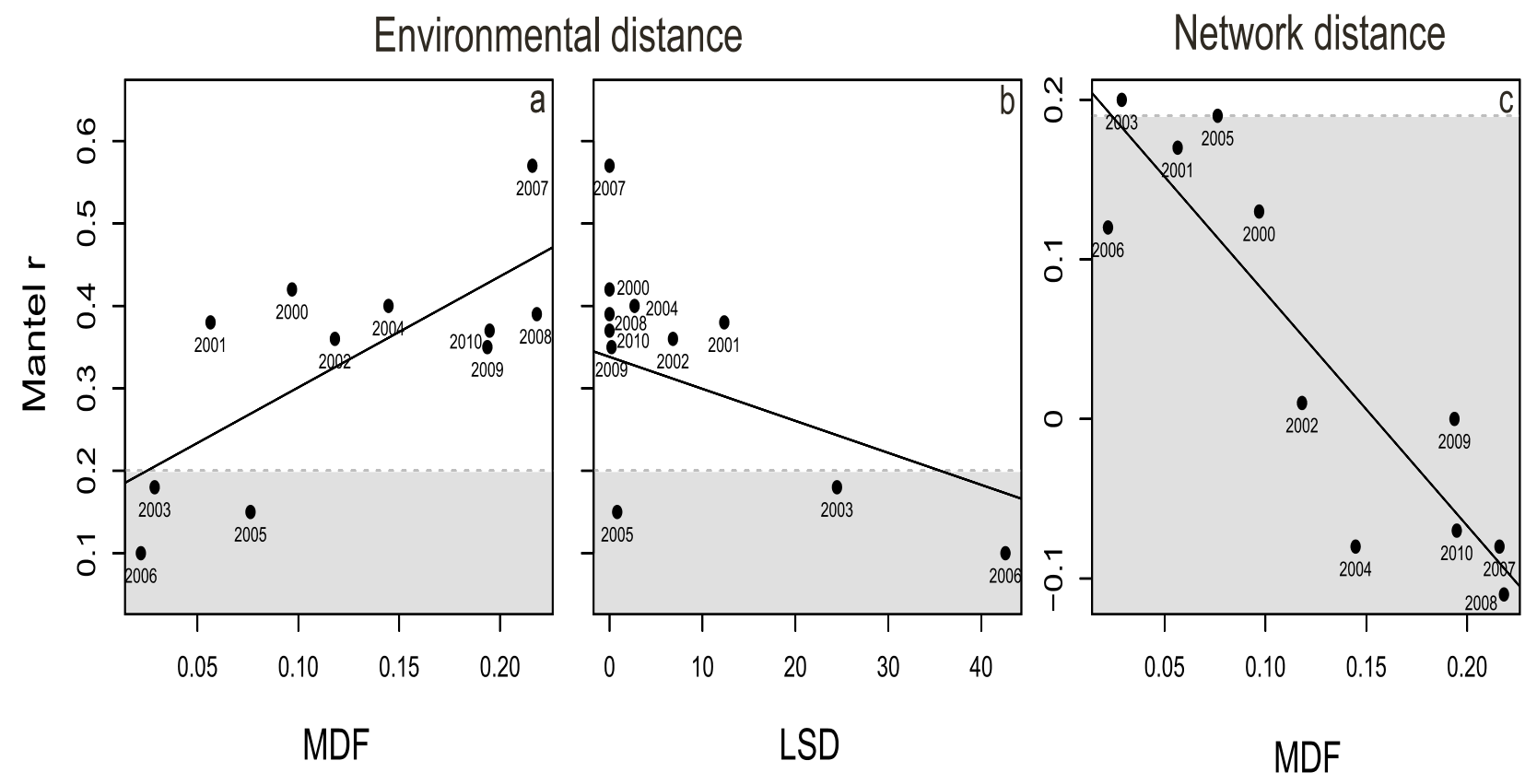

'This article is protected by copyright. All rights reserved.' 
Fig.4: Linear regressions between mean annual occupancy of rare (frequency $<0.05$ to 0.2 ; squares, dotted line), intermediate ( 0.4 to 0.6 ; triangles, dashed line) and common (>0.8; dots, solid line) species vs. annual averages for (a) greatest rate of rise (GRR, $\mathrm{m}^{3} / \mathrm{day}$ ), (b) mean daily flow (MDF, $\mathrm{m}^{3} / \mathrm{s}$ ), and (c) deviation of observed $\beta$-diversity from null expectation (SES values).
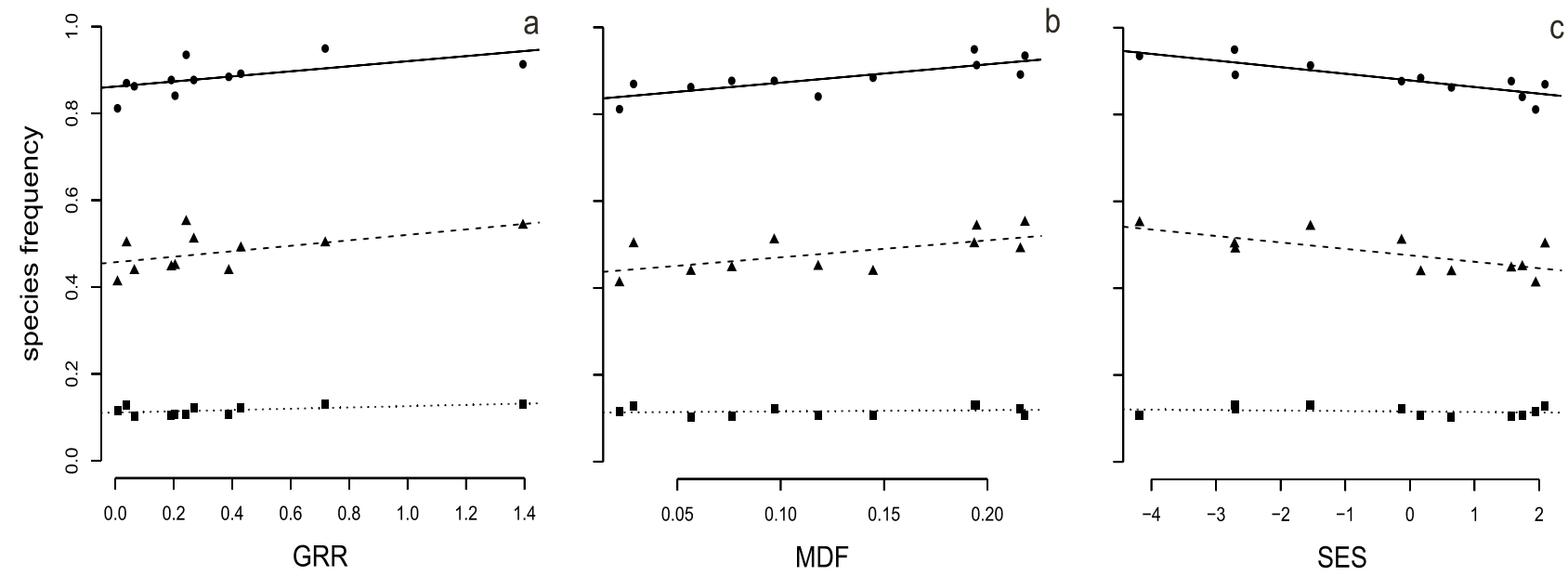

'This article is protected by copyright. All rights reserved.' 
Fig. 5: Best (based on AIC) linear regressions between mean annual occupancy of two common $(a, b)$, two intermediate $(c, d)$ and two rare $(e, f)$ taxa vs. annual averages of flow variables. $\mathrm{MDF}=$ mean daily flow, $\mathrm{LSD}=$ low-flow spell total duration $(\mathrm{LSD}) . \mathrm{R}^{2}$ of the linear regressions are also reported.
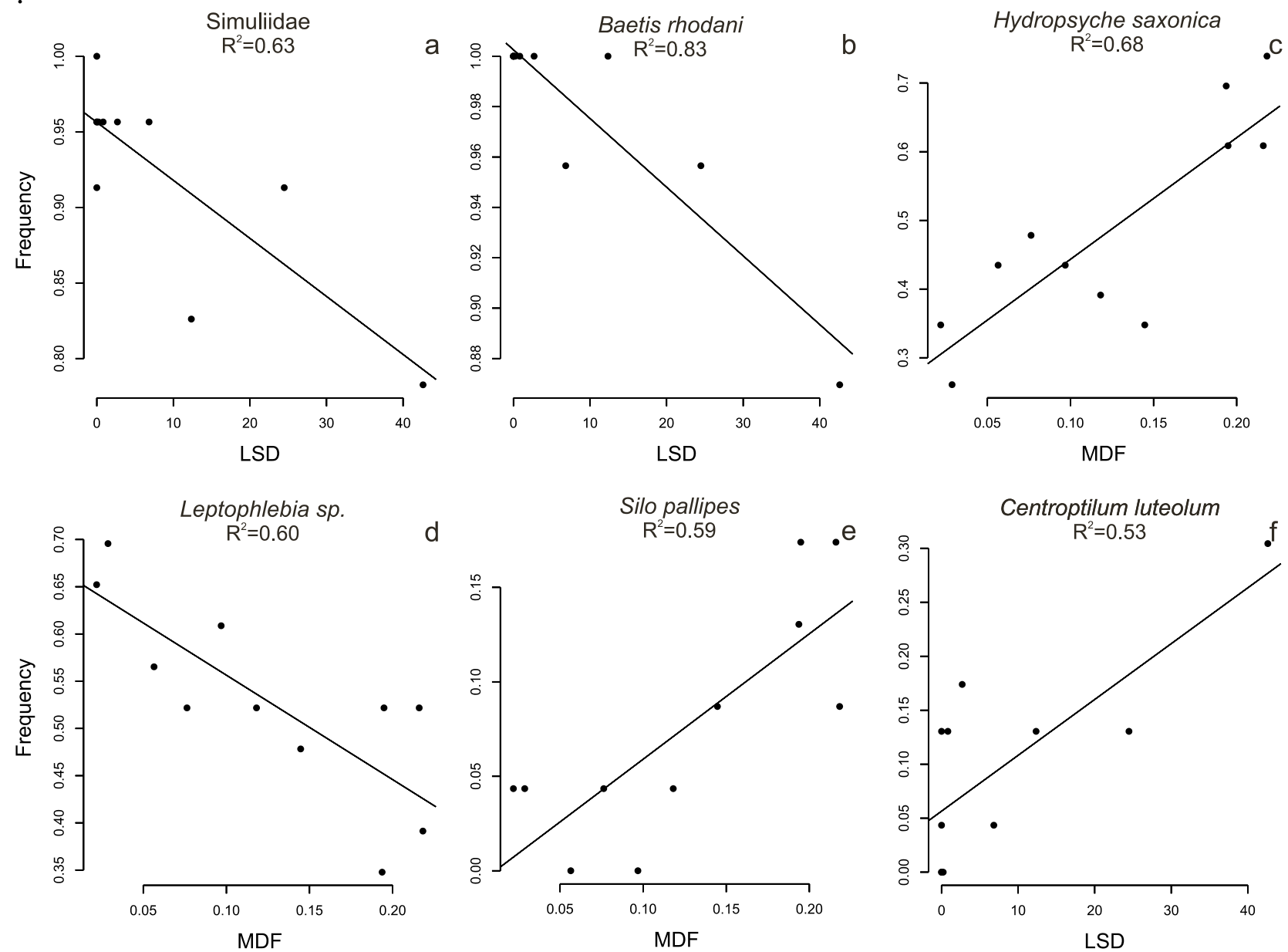

'This article is protected by copyright. All rights reserved.' 


\section{Table Legends}

Table 1: Average ( $\pm 1 \mathrm{SE})$ observed species richness, cumulative (regional) richness, average observed $\beta$-diversity (Sorensen dissimilarities) and predicted $\beta$-diversity (null $\beta$ ) in each study year, together with deviations from null (standardized effect sizes, SES), 95\% confidence intervals of simulated dissimilarities $(n=999)$ and associated $P$ values. $\beta$-diversity was calculated on rarefied data (sample size: 300 individuals). $\mathrm{P}$ values were calculated by comparing the observed mean $\beta$-diversity to $95 \%$ confidence intervals derived from the

\begin{tabular}{lllllllll}
\hline Year & $\begin{array}{l}\text { Mean } \\
\text { richness }\end{array}$ & $\begin{array}{l}\text { Cumulative } \\
\text { richness }\end{array}$ & $\begin{array}{l}\text { Mean } \\
\text { observed } \boldsymbol{\beta}\end{array}$ & $\begin{array}{l}\text { Mean } \\
\text { null } \boldsymbol{\beta}\end{array}$ & SES & $\mathbf{2 . 5 0 \%}$ & $\mathbf{9 7 . 5 0 \%}$ & $\boldsymbol{P}$ \\
\hline $\mathbf{2 0 0 0}$ & $27( \pm 1.2)$ & 80 & 0.481 & 0.482 & -0.130 & 0.455 & 0.511 & 0.907 \\
$\mathbf{2 0 0 1}$ & $27( \pm 1.0)$ & 79 & 0.499 & 0.490 & 0.642 & 0.463 & 0.517 & 0.559 \\
$\mathbf{2 0 0 2}$ & $27( \pm 1.3)$ & 84 & 0.521 & 0.497 & 1.739 & 0.469 & 0.523 & 0.077
\end{tabular}

randomly generated null $\beta$ for each year. $\mathrm{P}$ values $<0.05$ are indicated in bold. 


$\begin{array}{lllllllll}\mathbf{2 0 0 3} & 30( \pm 1.3) & 83 & 0.500 & 0.473 & 2.091 & 0.448 & 0.499 & \mathbf{0 . 0 3 9} \\ \mathbf{2 0 0 4} & 28( \pm 1.1) & 81 & 0.490 & 0.487 & 0.167 & 0.457 & 0.515 & 0.873 \\ \mathbf{2 0 0 5} & 26( \pm 1.2) & 84 & 0.514 & 0.492 & 1.569 & 0.464 & 0.519 & 0.111 \\ \mathbf{2 0 0 6} & 23( \pm 1.7) & 70 & 0.545 & 0.517 & 1.946 & 0.488 & 0.545 & 0.053 \\ \mathbf{2 0 0 7} & 27( \pm 1.2) & 76 & 0.448 & 0.486 & -2.703 & 0.458 & 0.513 & \mathbf{0 . 0 1 1} \\ \mathbf{2 0 0 8} & 30( \pm 0.8) & 78 & 0.413 & 0.469 & -4.184 & 0.441 & 0.494 & \mathbf{0 . 0 0 1} \\ \mathbf{2 0 0 9} & 32( \pm 0.9) & 78 & 0.433 & 0.468 & -2.715 & 0.446 & 0.494 & \mathbf{0 . 0 0 9} \\ \mathbf{2 0 1 0} & 33( \pm 1.2) & 79 & 0.449 & 0.469 & -1.539 & 0.444 & 0.496 & 0.109\end{array}$


Table 2: Mantel correlations between the $\beta$ deviation (pairwise deviations from null models) matrix and environmental (flow-related) and network distance matrices for each study year. Mantel correlations between network and environmental distances are also given. Also indicated are the variables included in the calculation of the environmental distance (selected using BIOENV) in each year. $\mathrm{MDF}=$ mean daily flow, $\mathrm{CV}=$ coefficient of variation of daily flow, HSD = total duration of high flow spells, LSD = total duration of low flow spells and GRR $=$ greatest rate of rise $\mathrm{P}$ values $<0.05$ are indicated in bold.

\begin{tabular}{ccc}
\hline Environmental & Network & $\begin{array}{c}\text { Network vs } \\
\text { environmental }\end{array}$
\end{tabular}

\begin{tabular}{llcccccc}
\hline Year & Selected variables & Mantel r & $\boldsymbol{P}$ & Mantel r & $\boldsymbol{P}$ & Mantel r & $\boldsymbol{P}$ \\
\hline 2000 & MDF, GRR & 0.42 & $\mathbf{0 . 0 0 3}$ & 0.13 & 0.137 & 0.17 & 0.124 \\
2001 & GRR & 0.38 & $\mathbf{0 . 0 0 3}$ & 0.17 & 0.081 & 0.10 & 0.223 \\
2002 & MDF, CV, HSD, GRR & 0.36 & $\mathbf{0 . 0 0 7}$ & 0.01 & 0.433 & 0.36 & $\mathbf{0 . 0 0 5}$ \\
2003 & MDF & 0.18 & 0.083 & $\mathbf{0 . 2 0}$ & 0.050 & 0.07 & 0.257 \\
2004 & MDF, HSD, LSD, & 0.40 & $\mathbf{0 . 0 0 2}$ & -0.08 & 0.780 & 0.47 & $\mathbf{0 . 0 0 1}$ \\
2005 & MDF, LSD & 0.15 & 0.109 & $\mathbf{0 . 1 9}$ & 0.041 & 0.03 & 0.385 \\
2006 & MDF, LSD & 0.10 & 0.20 & 0.12 & 0.158 & 0.25 & $\mathbf{0 . 0 3 4}$ \\
2007 & MDF, CV, GRR & 0.57 & $\mathbf{0 . 0 0 1}$ & -0.08 & 0.758 & 0.30 & $\mathbf{0 . 0 1 5}$ \\
2008 & MDF, CV, GRR & 0.39 & $\mathbf{0 . 0 0 3}$ & -0.11 & 0.815 & 0.28 & $\mathbf{0 . 0 3 2}$ \\
2009 & MDF, CV, GRR & 0.35 & $\mathbf{0 . 0 0 5}$ & 0.00 & 0.506 & 0.40 & $\mathbf{0 . 0 0 5}$ \\
2010 & MDF, CV & $\mathbf{0 . 0 0 2}$ & $\mathbf{0 . 0 0 2}$ & -0.07 & 0.735 & 0.32 & $\mathbf{0 . 0 0 3}$ \\
\hline
\end{tabular}

